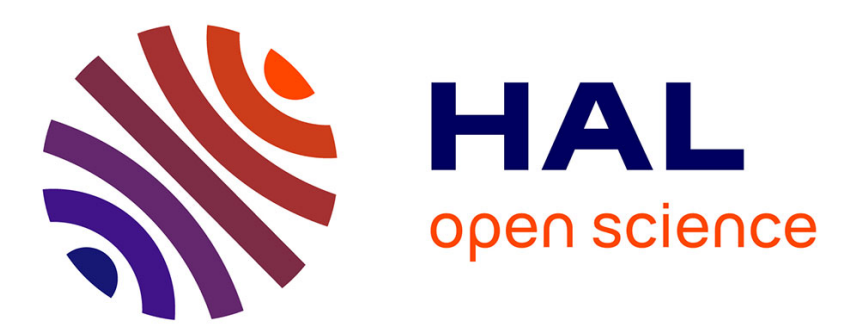

\title{
A physical model for high resolution radar sea clutter
}

Floriane Madeleine Schreiber, Sébastien Angelliaume, Charles-Antoine Guérin

\section{To cite this version:}

Floriane Madeleine Schreiber, Sébastien Angelliaume, Charles-Antoine Guérin. A physical model for high resolution radar sea clutter. 2019 International Radar Conference (RADAR), Sep 2019, TOULON, France. pp.1-4, 10.1109/RADAR41533.2019.171408 . hal-02615119

\section{HAL Id: hal-02615119 https://hal.science/hal-02615119}

Submitted on 8 Sep 2021

HAL is a multi-disciplinary open access archive for the deposit and dissemination of scientific research documents, whether they are published or not. The documents may come from teaching and research institutions in France or abroad, or from public or private research centers.
L'archive ouverte pluridisciplinaire HAL, est destinée au dépôt et à la diffusion de documents scientifiques de niveau recherche, publiés ou non, émanant des établissements d'enseignement et de recherche français ou étrangers, des laboratoires publics ou privés. 


\section{A physical model for high resolution radar sea clutter}

\author{
Floriane Madeleine Schreiber \\ DEMR - ONERA \\ F-13661 Salon cedex Air - France \\ Univ. Toulon, Aix Marseille Université \\ CNRS, IRD, MIO UM 110 \\ La Garde, France \\ floriane.schreiber@onera.fr
}

\author{
Sébastien Angelliaume \\ DEMR - ONERA \\ F-13661 Salon cedex Air - France \\ sebastien.angelliaume@onera.fr
}

\author{
Charles-Antoine Guérin \\ Univ. Toulon, Aix Marseille Université \\ CNRS, IRD, MIO UM 110 \\ La Garde, France \\ charles-antoine.guerin@univ-tln.fr
}

\begin{abstract}
Sea clutter intensity for high-resolution imaging radars is known to deviate from the classical exponential probability distribution which is observed at low resolution. We use a physical description of sea clutter based on the Two-Scale Model to obtain a relevant expression of the clutter distribution at high-resolution. We test this model with a set of airborne SAR data and show that it provides excellent fits of the intensity distribution in the two polarizations with only one parameter, which is interpreted as a surface mean square slope and is sea state dependent.
\end{abstract} Keywords-Sea clutter, radar image, high resolution

\section{INTRODUCTION}

Sea clutter discrimination is a key issue for target identification in a maritime environment with imaging radars. This discrimination is usually based on the statistics of pixel intensity. At low spatial resolution the pixel intensity is known to follow an exponential probability distribution. However, as the resolution increases, it is better represented by heavy tail distributions. Today, a wide variety of empirical distributions has been proposed to fit the observed data (e.g. [1]).

In this work, we rather use a physical description of sea clutter to characterize the intensity distribution. It is based on the Two-Scale Model (TSM) and leads to the so-called compound probability distribution ([2], [3], [4]). We apply this simple model to a set of high-resolution airborne SAR data and obtain excellent fits of the clutter distribution in the main two polarizations using a unique parameter, which is interpreted as a surface mean square slope in the radar look direction.

\section{THE COMPOUND DISTRIBUTION MODEL}

In high-resolution the radar reflectivity can be described in terms of a Two-Scale Model (TSM [5]) in which the elementary rough facets have the same order of magnitude as pixel size. In this model the Normalized Radar Cross Section (NRCS, $\sigma_{0}^{L}(\theta)$ ) from the sea surface is obtained by an incoherent average of the cross-section of tilted rough facets. For a single facet of size $\mathrm{L}$ and slope $\mathrm{s}$, the fluctuations of pixel intensity are exponentially distributed about a mean quantity $\sigma_{0}^{L}(\theta ; s)$ referred to as the texture, which is the local NRCS attributed to the facet. When the random fluctuations of the facet slope s are taken into account, this leads to a compound probability distribution for the pixel intensity:

$$
p d f(I)=\int \frac{1}{\tau(\theta ; \vec{s})} \exp \left(-\frac{I}{\tau(\theta ; \vec{s})}\right) p d f(\vec{s}) d \vec{s}
$$

where

$$
\tau(\theta, \vec{s})=\frac{\sigma_{L}^{0}(\theta ; \vec{s})}{\sigma_{L}^{0}(\theta)}(2)
$$

is a dimensionless quantity which we refer to as the "texture" parameter. Here the intensity has been normalized by the NRCS (so that the model does not depend on any absolute calibration).

To apply this model, we assume that the facet slope distribution is Gaussian and characterized by its mean square slopes $\left(m s s_{x}, m s s_{y}\right)$ along the $x$ and $y$ axis of a Cartesian horizontal coordinates system. We will here adopt the convention that the $x$-axis is directed along the radar line of sight and the $y$-axis crosswise to the radar aim direction

The local facet cross section, $\sigma_{L}^{0}$, is given by the tilted Bragg model. Its general expression can be found in [5] and is combined with the classical Elfouhaily spectral model [6]. The compound distribution of the normalized intensity $I$ can thus be calculated by direct integration of (1). In testing the model we observed that the $m s s_{y}$ parameter (that is, the mss perpendicular to the radar look direction) has virtually non influence on the intensity distribution while the latter is very sensitive to the $m s s_{x}$ parameter (that is the mss in the radar look direction). We therefore ignored the $m s s_{y}$ parameter in the computations (by setting its value to $m s s_{x}$ ).

We also observed that the employed spectral model has little influence on the distribution of normalized intensity. Hence the model admits a unique effective parameter, $m s s_{x}$.

Given the dynamical range of the backscattered intensity it is convenient to express it in $\mathrm{dB}$ providing a simple change of variable for the corresponding pdf:

$$
p d f\left(I_{d B}\right)=\frac{\log _{10}}{10} \operatorname{Ipd} f(I)
$$

\section{ASSESSMENT OF THE MODEL}

\section{A. The experimental data set}

Experimental data are used in this paper to evaluate the accuracy of the proposed model to represents actual radar sea clutter. They were collected by SETHI, the airborne remote sensing radar developed by ONERA [7]. It is a pod-based multi-frequency high resolution SAR system designed to explore the scientific applications of remote sensing. SAR 
data have been acquired at two different geographical positions along the French coast, the Atlantic Ocean and the Mediterranean Sea.

The first data set in Figure 1, is polarimetric SAR data, collected at X-band over the English Channel with a high sea state $\left(U_{10}=10.2 \mathrm{~m} . \mathrm{s}^{-1}\right)$, an incidence angle of $70^{\circ}$ and a spatial resolution of $0.5 \mathrm{~m}$ in both range and azimuth directions. Several linear acquisitions were made with flight headings varying by steps of $22.5^{\circ}$ to explore azimuth variation.
The second data set in Figure 2, is dual-frequency SAR data collected simultaneously at X- and L-band over the Mediterranean Sea with a moderate sea state ( $\left.U_{10}=8.5 \mathrm{~m} \cdot \mathrm{s}^{-1}\right)$ and an incidence angle of $45^{\circ}$. The spatial resolution in both directions was equal to $0.5 \mathrm{~m}$ at $\mathrm{X}$-band and $1 \mathrm{~m}$ at L-band. Only one linear flying trajectory is available, resulting in a crosswind observation.

The wind and wave information were obtained from MétéoFrance, the French national meteorological service and is given in Table I.

Properties of THE SETHI SeA ClUtTER ACQUISITIONS INVESTIGATED IN THIS PAPER

\begin{tabular}{|c|c|c|c|c|c|c|c|}
\hline Area & $\begin{array}{c}\text { Polarizatio } \\
\text { n }\end{array}$ & $\begin{array}{c}\text { Frequency } \\
\text { band }\end{array}$ & $\begin{array}{c}\text { Spatial } \\
\text { resolution } \\
\text { (m) }\end{array}$ & $\begin{array}{c}\text { Incidence } \\
\text { angle (deg) }\end{array}$ & $\begin{array}{c}\text { Wind speed } \\
\left(\mathrm{m} . \mathrm{s}^{-1}\right)\end{array}$ & $\begin{array}{c}\text { Wave height } \\
\text { (m) }\end{array}$ & Look direction \\
\hline Atlantic & & $\mathrm{X}$ & 0.5 & 70 & 10.2 & 3.6 & varying \\
\hline \multirow{3}{*}{ Mediterranean } & $\mathrm{HH}+\mathrm{VV}$ & $\mathrm{X}$ & 0.5 & \multirow{3}{*}{45} & \multirow{3}{*}{8.5} & \multirow{3}{*}{1.1} & \multirow{3}{*}{ Cross-wind } \\
\hline & & & & & & & \\
\hline & & $\mathrm{L}$ & 1 & & & & \\
\hline
\end{tabular}

Table 1. Properties of the sea clutter acquisition investigated in this paper
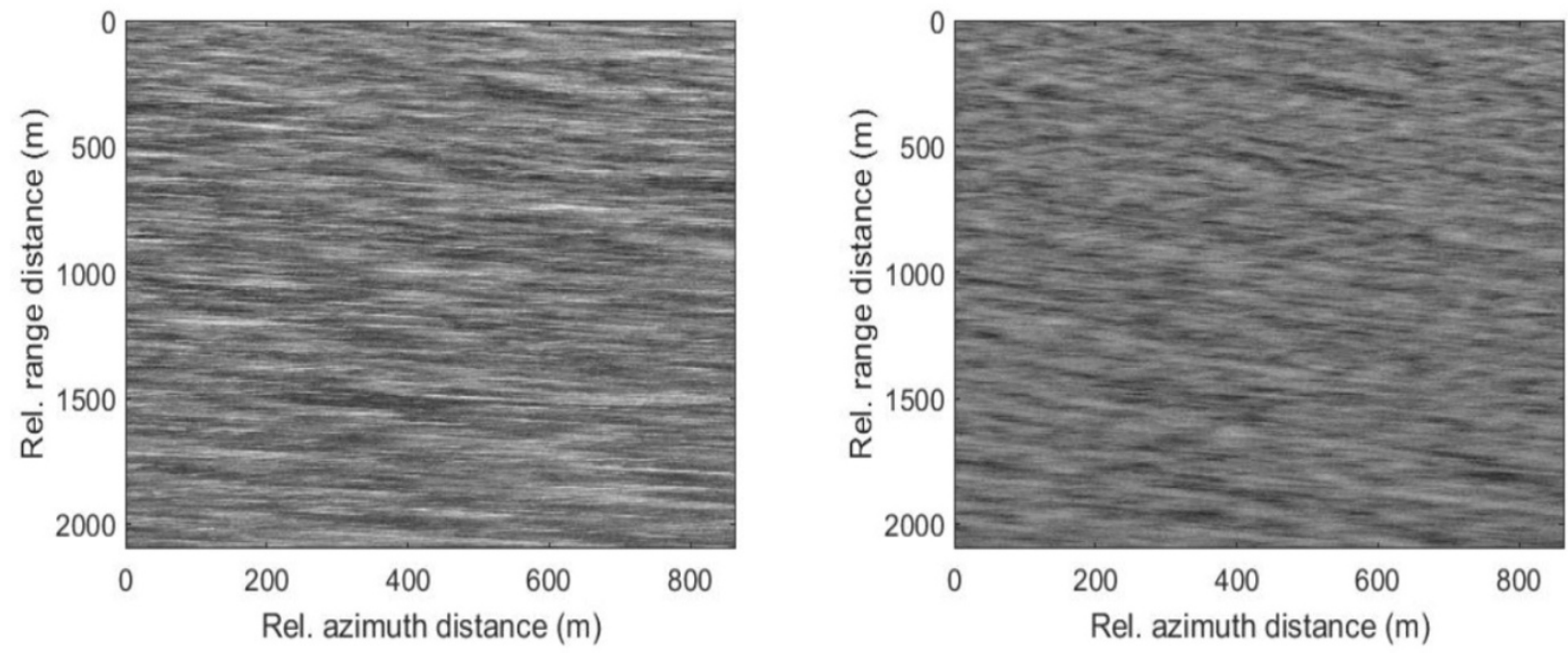

Figure 1. X-band SAR data collected over the Atlantic Ocean with (left) HH-pol and (right) VV-pol. Incidence $70^{\circ}, U_{10}=10.2 \mathrm{~m} . \mathrm{s}^{-1}$, upwind.
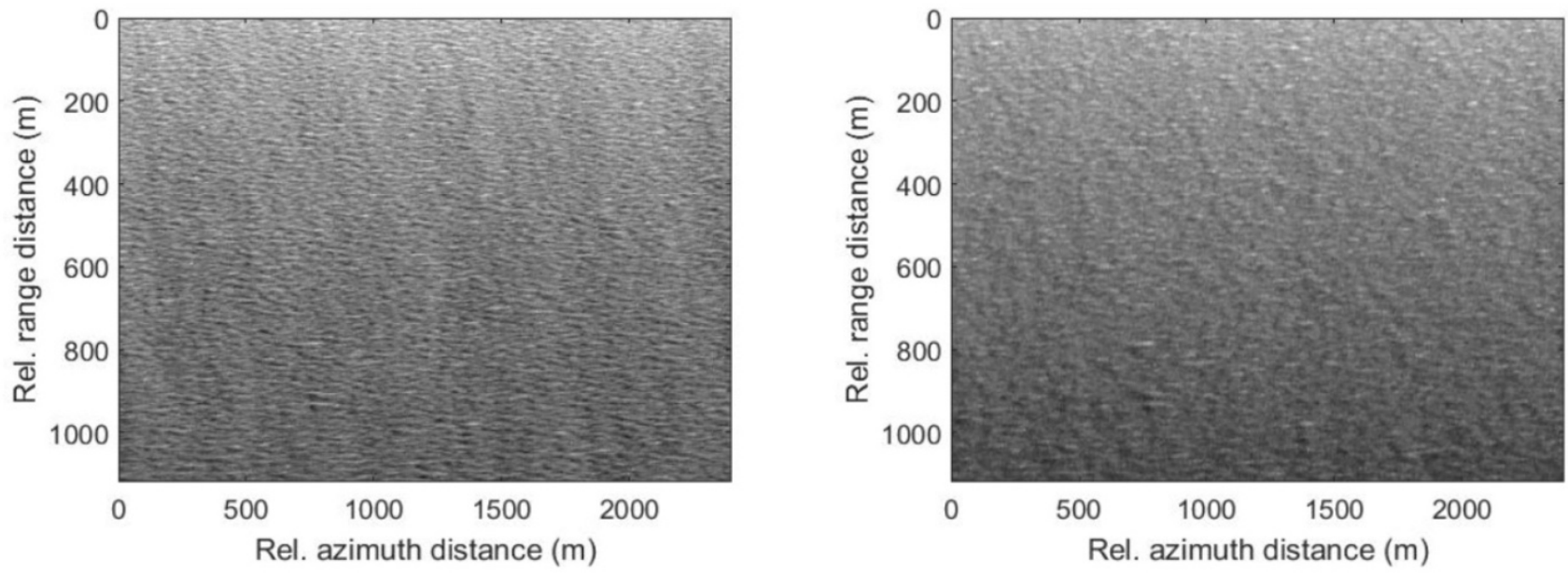

Figure 2. SAR data collected over the Mediterranean Sea at (left) X-band and (right) L-band. HH-pol, incidence $45^{\circ}$, $U_{10}=8.5$ m. ${ }^{-1}$, crosswind. 


\section{A. Model fitting}

The Bhattacharya distance is used to calculate the similarity between two PDF $m(x)$ and $d(x)$ :

$$
D_{B}(m, d)=-\ln \left(C_{B}(m(x), d(x))\right)
$$

It is related to the Bhattacharya coefficient $C_{B}$ which measure the overlap quantity between the two statistical samples:

$$
C_{B}(m, d)=\int \sqrt{m(x) d(x)} d x
$$

The empirical distribution of the intensity data has first been evaluated and the Bhattacharya distance $\left(D_{B}\right)$ has been minimized with respect to the trial values of mss $_{\mathrm{x}}$ for each polarization.

For the data in the Atlantic Ocean, in X-Band with a grazing angle of $70^{\circ}$ and a strong sea state, the model fits with the data (Fig 4). The $D_{B}$ is equal to $-30 \mathrm{~dB}$ and $-29.4 \mathrm{~dB}$ in $\mathrm{HH}$ and VV-pol respectively.

For the other data in the Mediterranean Sea, in X-Band, as we see in the Figure 5, the model fits with the data. The $D_{B}$ is equal to $-30.1 \mathrm{~dB}$ and $-30.8 \mathrm{~dB}$ in $\mathrm{HH}$ and VV-pol respectively. For the data acquired at the same place but in LBand, we see in the Figure 5, that the model fits also well with the data. For this band of frequency, the $D_{B}$ is equal to 29.8dB and -29.9 dB in $\mathrm{HH}$ and VV-pol respectively.

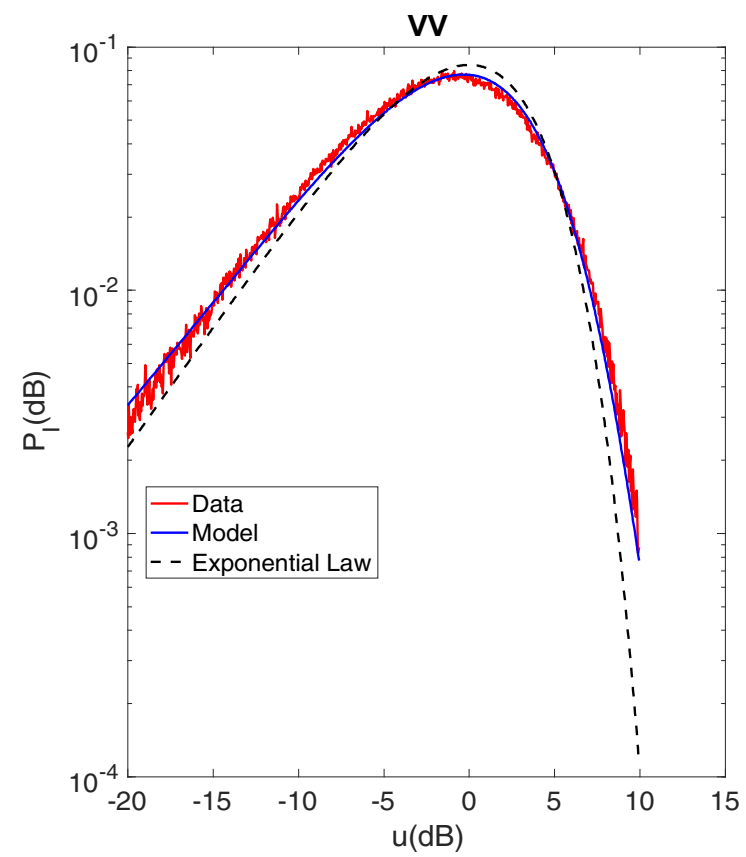

Figure 4. Illustration of model fitting - Atlantic Ocean : X-Band, Incidence $70^{\circ}, U_{10}=10.2 \mathrm{~m} \cdot \mathrm{s}^{-1}$. Actual radar data (red), model (blue), exponential law (black dash)
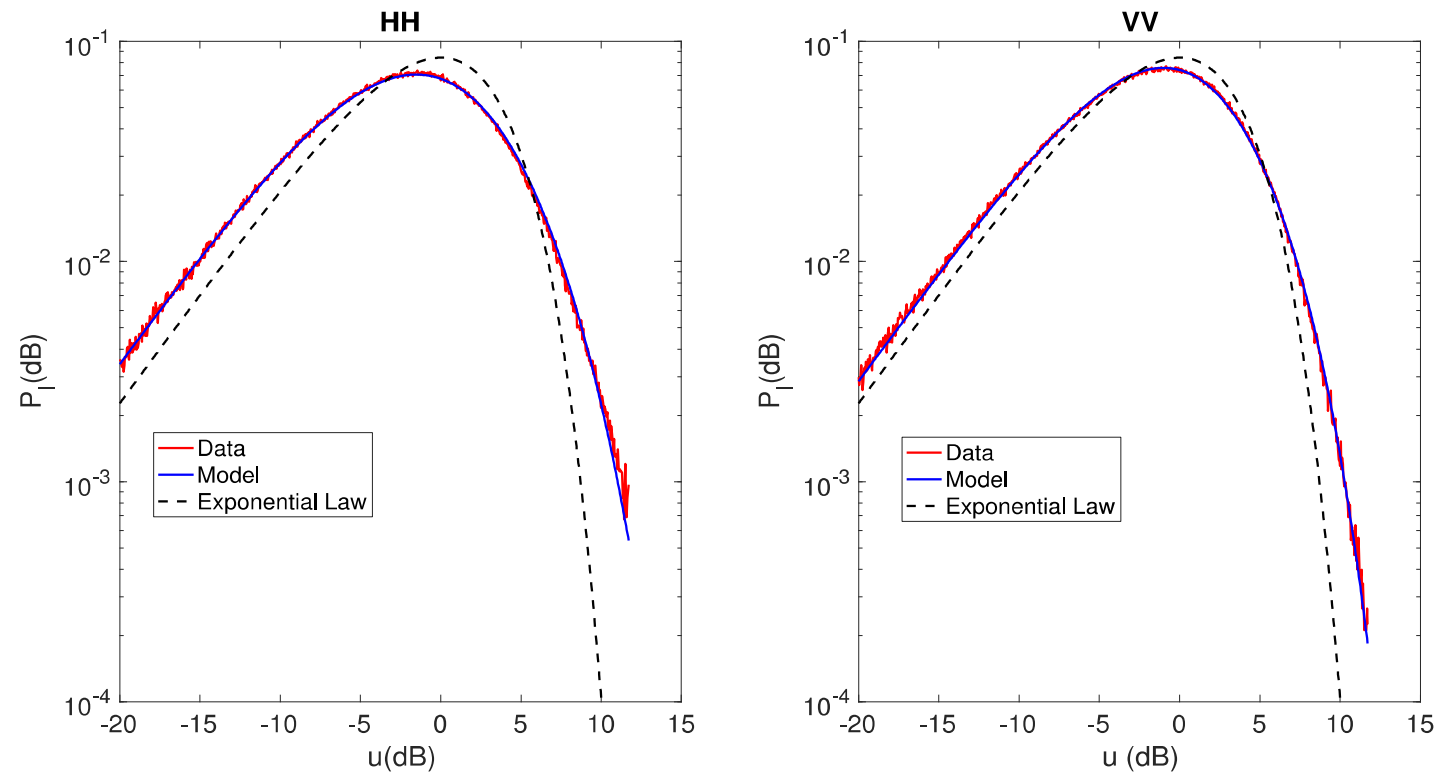

Figure 5. Illustration of model fitting - Mediterranean Sea: X-Band, Incidence $45^{\circ}, U_{10}=8.5 \mathrm{~m} \cdot \mathrm{s}^{-1}$. Actual radar data (red), model (blue), exponential law (black dash) 

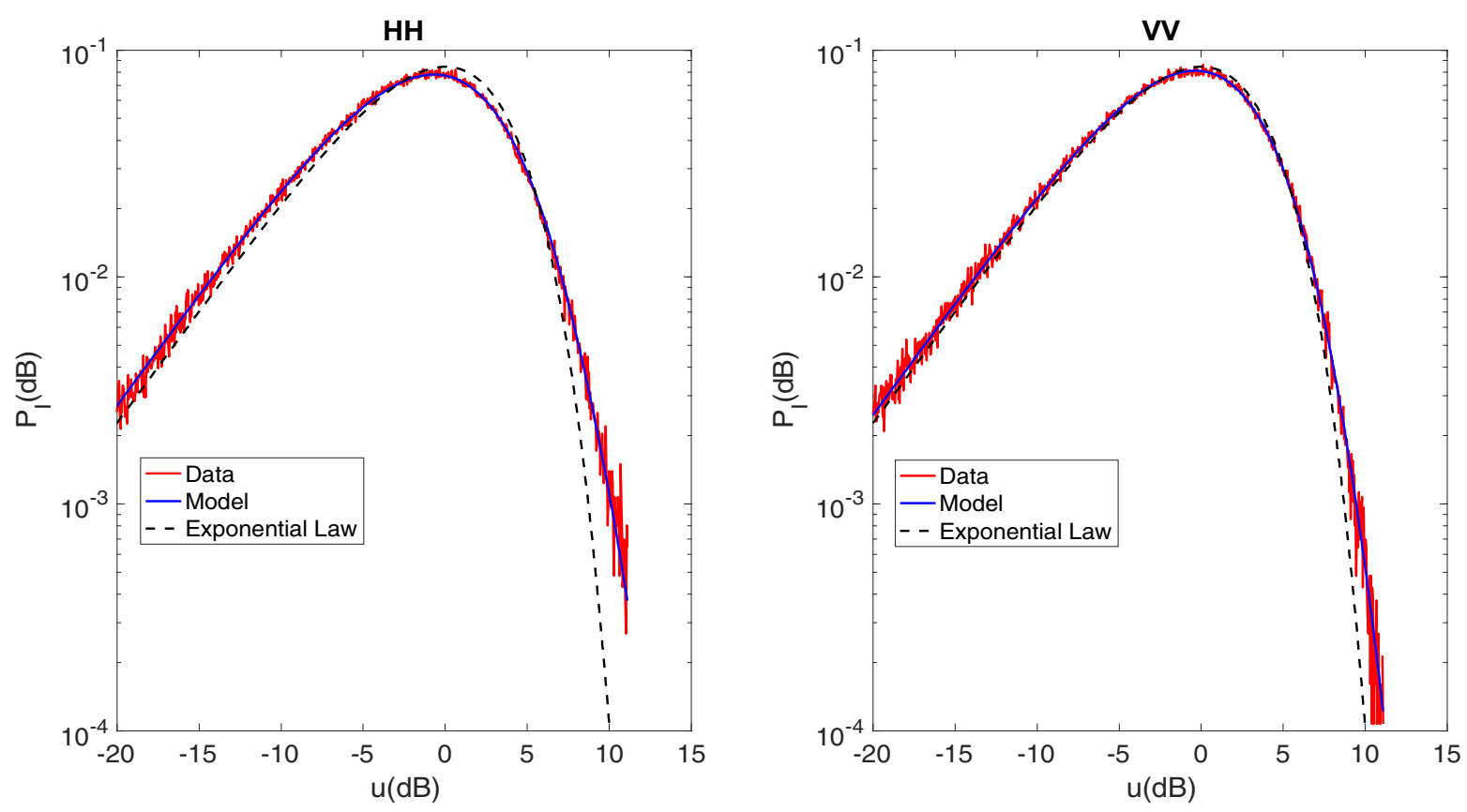

Figure 6. Illustration of model fitting - Mediterranean Sea: L-Band, Incidence $45^{\circ}, U_{10}=8.5 \mathrm{~m} \cdot \mathrm{s}^{-1}$. Actual radar data (red), model (blue), exponential law (black dash)

The values of the IIIss $_{\mathrm{x}}$ that allow a perfect fit to the empirical distribution of intensities are found to depend on the radar frequency, polarization, incidence angle and sea state. However, their values have the expected order of magnitude ( $5.10^{-4}-3.10^{-3}$ ) for filtered slopes.

Investigation is in progress to establish a precise relationship between these fitting values and the sea state for a given radar geometry.

\section{CONCLUSION/Discussion}

A physical model, based on a classical Two-Scale representation of the ocean surface, has been used to fit highresolution airborne SAR data. This model is controlled by only one parameter which is linked to the sea state and is robust to the calibration of the radar. The accuracy of the proposed model to represent actual radar sea clutter has been assessed using one measure of goodness of fit (the Bhattacharyya Distance) with radar data collected at X- and L-Band with different sea states and acquisition geometries.

\section{ACKNOWLEDGMENT}

The authors would like to thank the Région Provence-AlpesCôte d'Azur for funding the Ph.D. thesis of F. Schreiber.

\section{REFERENCES}

[1] K. D. Ward, R. J. A. Tough, and S. Watts. Sea clutter: Scattering, the k-distribution and radar performance. 2nd ed. Herts, U.K.: The Institute of Engineering Technology, 2013.

[2] GR Valenzuela and MB Laing. On the statistics of sea clutter. Technical report, Naval Research Lab Washington DC, 1971.
[3] BL Gotwols and DR Thompson. Ocean microwave backscatter distributions. Journal of Geophysical Research: Oceans, 99(C5):9741-9750, 1994.

[4] Hongkun Li and Joel T Johnson. On the amplitude distributions of bistatic scattered fields from rough surfaces. IEEE Transactions on Geoscience and Remote Sensing, 55(12):6883-6892, 2017.

[5] G. Valenzuela. Theories for the interaction of electromagnetic and oceanic waves - a review. BoundaryLayer Meteorology, 13, 1978.

[6] T. Elfouhaily, B. Chapron, K. Katsaros, and D. Vandemark. A unified directional spectrum for long and short wind-driven waves. J. Geophys. Res., 102, 1997.

[7] S. Angelliaume, X. Ceamanos, F. Viallefont-Robinet, R. Baqué, P. Déliot and V. Miegebielle, "Hyperspectral and Radar Airborne Imagery over Controlled Release of Oil at Sea,"in Sensors, 1772, 2017. 